\title{
Technology Acceptance Model-Based Research on Differences of Enterprise Resources Planning Systems Use in India and the European Union
}

\author{
Simona Sternad Zabukovsek ${ }^{1}$, Sangeeta Shah Bharadwaj ${ }^{2}$, Samo Bobek $^{3}$, Tjasa Strukelj ${ }^{4}$ \\ 1,3,4 University of Maribor \\ Razlagova 14, 2000 Maribor, Slovenia \\ E-mail. ${ }^{1}$ simona.sternad@um.si, ${ }^{3}$ samo.bobek@um.si, ${ }^{4}$ tjasa.strukelj@um.si \\ ${ }^{2}$ Management Development Institute (MDI) \\ Mehrauli Road, Sukhrali, Gurgaon - 122 007, India \\ E-mail.ssbharadwaj@mdi.ac.in \\ cross $^{\text {ref }}$ http://dx.doi.org/10.5755/j01.ee.30.3.21211
}

Acceptance of enterprise resources planning (ERP) systems remains among the major concerns of organisations in the global economy. In the past, research has primarily focused on ERP systems in the early stages of their life-cycle. Because ERP systems are no longer new for organisations, recent research attempts are focused on their use in the maturity stage and different environments. In the article, we compared the results of two studies focused on ERP advanced use in their maturity stage in two different but important socio-economic cultural backgrounds. This has, from the research perspective and to the best of our knowledge, not yet been compared. Thus, the purpose of this study was to research whether and to what extent users' extensive and explorative use of the ERP system differs in various regions. The main objective of this study was to reveal determinants that have an impact on user acceptance of ERP systems and the extended use in different cultural environments - in the EU (developed countries) and India (developing country). The research was based on an extended technology acceptance model (TAM), where two additional factors (work compatibility and extended use) were added together with additional external factors that can influence users' acceptance of ERP systems. We analysed and compared the data of 444 ERP users from 14 organisations in the EU and 577 ERP users from 13 organisations in India. Even though the use of ERP systems in India and the EU is at the same advanced level, ERP users exhibit various behaviours and focus attention on different factors. Research data shows differences regarding the impact of extended TAM model factors and some differences regarding the impact of external factors researched.

Keywords: Enterprise Resource Planning (ERP); Technology Acceptance Model (TAM); Partial Least Squares (PLS) Modelling; Maturity Model; Organisational Culture; Cultural Differences.

Abbreviations used: AT (attitude toward use), ERP(enterprise resource planning), ExU (extended use), IS (information system), IT (information technology), OPC (organisational-process characteristics), PCIL (personal characteristics and information literacy), PEOU (perceived ease of use), PLS (partial least squares), PU (perceived usefulness), STC (system and technological characteristics), TAM (technology acceptance model), WC (work compatibility)

\section{Introduction}

Acceptance of information technologies (IT) and systems (IS) in organisations influences the level of benefits an organisation can expect from IT/IS used. Most of the organisations globally use, at the operational level, so-called enterprise resource planning (ERP) systems, which are IS that typically consist of a wide set of management tools that empower business functions in organisations in a way to enable employees to better conduct their work. ERP systems are standard software solutions that consist of different modules (purchase, production, sales, etc.). Organisations implement ERP systems to improve efficiency and become more responsive. The same ERP systems are used in organisations worldwide, including in Europe and India. In fact, they have become the de facto standard for the replacement of legacy IS not only in large organisations, particularly multinationals, but over the last several years in small and medium-size organisations. As several studies have revealed, a common reason for ERP failures can be attributed to users' reluctance and unwillingness to adopt and to use an implemented ERP system (Hancerliogullari Koksalmis \& Damar, 2019; Huang \& Yasuda, 2016; Isnalita, 2018; Nah et al., 2004; Rajan \& Baral, 2015; Schlichter \& Kraemmergaard, 2010; Umble et al., 2002).

Acceptance of IT/IS has been researched over long periods of time; further, researchers have used several theoretical models to study acceptance and the use of new IT/IS, such as the theory of reasoned action (TRA; Fishbein \& Ajzen, 1975), the theory of planned behaviour (TPB; Ajzen, 1991), the theory of the technology acceptance model (TAM; Davis et al., 1989), etc. Compared with competing research models, TAM is believed to be more parsimonious, predictive, and robust (Venkatesh \& Davis, 2000) and thus, among theoretical models, is most widely used by researchers (Amoako-Gyampah \& Salam, 2004; Davis, 1989; Davis et al., 1989; Huang \& Yasuda, 2016; Lee et al., 2010). TAM posits that two beliefs - perceived usefulness (PU) and perceived ease of use (PEOU) - are of primary relevance for 
computer acceptance behaviour (Davis et al., 1989). The purpose of TAM is also to provide a basis for tracing the impact of external factors on internal beliefs, attitudes, and intentions (Davis et al., 1989). The TAM is well established and tested; furthermore, a variety of extensions regarding external factors by examining the antecedents of PU and PEOU has been developed. Venkatesh and Davis (2000) proposed an extension of TAM - TAM2 by identifying general determinants of PU, which are the subjective norm, image, job relevance, output quality, results demonstrability, and PEOU. Venkatesh and Davis (2000) developed a model of the determinants of PEOU, which are computer selfefficacy, computer anxiety, computer playfulness, and perceptions of external control (or facilitating conditions). Venkatesh and Bala (2008) combined TAM2 and the model of the determinants of PEOU and developed an integrated model of technology acceptance, i.e., TAM3. We extended the TAM model with additional external factors related to ERP systems acceptance (Figure 1). Validation of the relationship between work compatibility (WC) and attitude toward ERP use (AT) on the extended ERP use (ExU) represent the novelty of the article.

Huang and Yasuda (2016), in their comprehensive review of 86 surveyed articles on ERP topics, pointed out that many research papers deal with pre-implementation and implementation phases of ERP implementation, while postimplementation research is in the initial stage. Only one-third of ERP implementation goes beyond the software focus of ERP implementation where business processes reengineering, and organisational change management should remain a focus (Panorama, 2010). Schlichter and Kraemmergaard (2010), in their comprehensive research of 885 peer-reviewed abstracts of journals from 2000 to 2009, also revealed research regarding optimisation of ERP systems, in which post-implementation, usefulness, achievement of competitive advantage through ERP, ERP users and financial benefits of ERP systems should be considered. Also, many other authors pointed out the problem of low exploitation of ERP systems, i.e., users don't use the implemented ERP solution to the advanced level (Bradford, 2008; Bueno \& Salmeron, 2008; Calisir et al., 2009; Costa et al., 2016; Hancerliogullari Koksalmis \& Damar, 2019; Hsieh \& Wang, 2007; Isnalita, 2018; Kwahk \& Lee, 2008; Rajan \& Baral, 2015; Scholtz, Mahmud, \& Ramayah, 2016; Uzoka et al., 2008). We are researching what problem is causing the differences.

The majority of conducted research studies used samples from a single country or single geographical area. Comparative analyses of ERP systems acceptance in two (several) countries or geographical areas are rare. Huang and Yasuda (2016) revealed that, among 86 literature reviews, only one paper (Moohebat et al., 2010) conducted the research that compared the difference of critical success factors between developed and developing countries. They added that looking for the distribution of research across geographical areas is a potential perspective of researching. ERP solutions are used globally. Because of their importance in the globalised world, we decided to compare ERP acceptance in the EU (already developed market) and India (developing market, where ERP solutions are quickly implementing). The scientific problem addresses the research question whether and to what extent the ERP system acceptance is extended, and explorative use can be measured with the same factors in different cultural environments. Does the use of the ERP systems differ in regions with different cultural backgrounds? This paper aims to present the research regarding the extended number of external factors that potentially influence attitude and behaviour related to extended ERP use. The main objective of this paper is to research differences regarding globally developed ERP system acceptance in organisations in the EU and India and to research factors that influence attitude and behaviour related to extended ERP use. External factors were divided into three groups (Sternad et al., 2011): personal characteristics and information literacy (PCIL); system and technological characteristics (STC); and organisationalprocess characteristics (OPC). The research model has been tested and applied in previous research conducted in the EU, i.e., 293 users have been involved in organisations where ERP systems use has been in its maturity stage (Sternad \& Bobek, 2013; 2014; Sternad et al., 2011). To gain insight into ERP acceptance in this stage, we replicated the survey in the EU in 2018 and carried it out for the first time in India in 2017. We collected survey data from 444 ERP users from 14 organisations in the EU and 577 users from 13 organisations in India. In both countries, ERP systems have been in their maturity stage. Based on our knowledge, no similar research comparing the EU and India users' acceptance of ERP systems influencing extended ERP use has been conducted. We researched different factors on which organisations in the EU and India should be focused to increase extended ERP use acceptance. A partial least-squares (PLS) modelling method has been used to analyse and discuss the data. A conceptual model, which takes into consideration interdependently the cumulative knowledge from TAM and ERP solutions research, has been developed and evaluated (PLS approach) to assess overall model fit to verify the causal relationships between factors. Two conducted studies have been compared and results analysed.

ERP solutions are global solutions, which have been implemented with ERP vendors methodologies (e.g., SAP has ASAP and Activate methodologies). Employees of organisations are mandated to use implemented ERP solutions. However, based on the research carried out, we discovered differences between researched geographical areas (developed countries in the EU versus developing countries, e.g., India). Researched factors of the extended TAM model are in both researched cases important and have an influence on extended ERP use (ExU), although the statistical significance of relationships between them differs. The important difference in researched models is that the factor attitude toward using ERP solution (AT) in the EU model is statistically significant and affected extended ERP use (ExU); however, in the India model, this relationship is not statistically significant. Even more, for ERP users in India, the importance of extended ERP use (ExU) is not as important as for users in the EU. Therefore, we propose that, in India, ERP vendors and organisations with implemented ERP solutions raise ERP users' awareness about the importance of extended ERP use for their organisations' practice. The same conclusion also came from Rajan and Baral (2015), who pointed out that organisations should realise the importance and identified variables in terms of characteristics on individual, organisational, and technological levels. From the studied external factors, there is an important difference 
between the EU and India in two factors included in the personal characteristics and information literacy (PCIL) group. In the EU model, the computer anxiety factor is statistically significant; while in India, this factor is not relevant. On the contrary, in India, the factor self-efficiency is important, which is not the case in the EU. The importance of self-efficiency in India was equally confirmed by Rajan and Baral (2015). The research also shows the different relationships importance of external factors on the extended TAM model. For this reason, ERP solutions vendors and organisations with implemented ERP solutions should emphasise factors that are perceived as more important in their culture. In this way, ERP users will be able to start using advanced ERP solution functionalities and take full advantage of them.

The rest of this paper is organised as follows: theoretical background and conceptual research model; sample and data collection; measurement model; structural model; discussion; and conclusion.

\section{Theoretical Background and Conceptual Research Model}

TAM is often used for researching ERP acceptance in organisations (Costa et al., 2016; Habjan et al., 2016; Hancerliogullari Koksalmis \& Damar, 2019; Hsu et al., 2015; Mayeh et al., 2016; Rajan \& Baral, 2015; Scholtz, Mahmud, \& Ramayah, 2016). TAM posits that two beliefs - perceived usefulness (PU) and perceived ease of use (PEOU) - are of primary relevance for computer acceptance behaviour (Davis et al., 1989). PU is defined as "the degree to which a person believes that using a particular system would enhance his or her job performance" (Davis, 1989). In contrast, PEOU refers to "the degree to which a person believes that using a system would be free of effort" (Davis, 1989). The two central hypotheses in TAM state that PU and PEOU positively influence an individual's attitude toward using a new technology (AT), which in turn influences his or her behavioural intention to use it. Finally, the intention is positively related to actual use. TAM also predicts that PEOU influences PU; as Davis et al. (1989) explained, "Effort saved due to improved PEOU may be redeployed, enabling a person to accomplish more work for the same effort."

TAM predicts the use and acceptance of IT/IS by individual users (Turner et al., 2010). The key purpose of TAM is to provide a basis for tracing the impact of external factors on internal beliefs, attitudes, and intentions (Davis, 1989; Davis et al., 1989). TAM and its upgrades have been applied to a variety of technologies (Amoako-Gyampah \& Salam, 2004; Costa et al., 2016; Davis, 1989; Davis et al., 1989; Hsu et al., 2009; Lee et al., 2010; Turner et al., 2010; Venkatesh \& Bala, 2008).

When reviewing past ERP literature studies regarding TAM, we found that different studies have researched ERP acceptance by users (Huang \& Yasuda, 2016; Schlichter \& Kraemmergaard, 2010). They have researched different issues of ERP use and have been focused on a small (limited) number of factors that have an influence on ERP acceptance in different phases of an ERP system life-cycle (Alhadi \& AlShaibany, 2017; Amoako-Gyampah \& Salam, 2004; Bazhair \& Sandhu, 2015; Bradley \& Lee, 2007; Bueno \& Salmeron, 2008; Calisir et al., 2009; Hancerliogullari Koksalmis \&
Damar, 2019; Hsieh \& Wang, 2007; Isnalita, 2018; Kwahk \& Lee, 2008; Lee et al., 2010; Mayeh et al., 2016; Nah et al., 2004; Sun et al., 2009; Uzoka et al., 2008; Youngberg et al., 2009; Weli, 2019).

The conceptual model of this research is presented in Figure 1. The grey area within the dotted line denotes the original TAM. The core of TAM is the behavioural intention to use, but this is not an appropriate measure if usage is mandated by the organisation (Habjan et al., 2016). If users accept the system and usage to become a day-to-day activity, there is no need to examine the behavioural intention on use; thus, the behavioural intention was dropped from the proposed research model. As mentioned previously, we examined the routine use of ERP systems (in the maturity stage), wherein ERP users should be acquainted with the system. Therefore, we researched extended use (ExU) rather than actual use (AT), as specified in the original TAM.

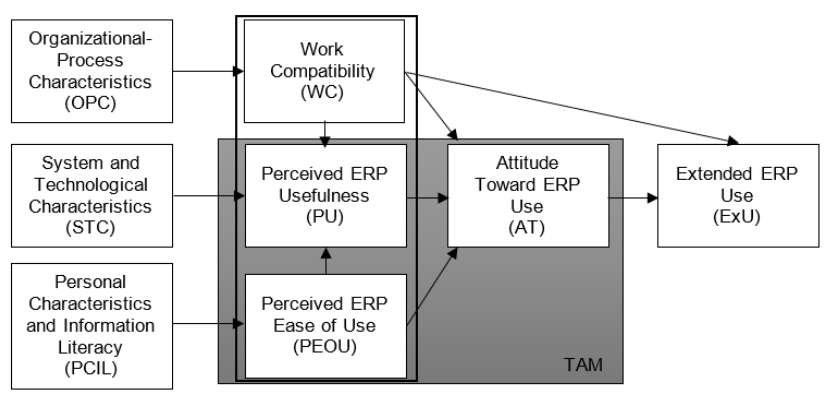

Figure 1. Conceptual Model

According to Davis and co-authors (1989), PEOU influences PU and both factors influence AT. The problem of TAM research is that most researchers examine a small number of external factors that influence user acceptance (AT). In the context of ERP systems, multiple external factors exist that can influence users' acceptance. Thus, the conceptualization of higher-order factors (in our case, second-order factors) must be researched if we want to understand user behaviour in ERP settings.

The constructs of the purposed model - PEOU, PU, and AT for basic TAM of ERP systems - are influenced by external factors, which are distributed among three second-order factors (Sternad et al., 2011): personal characteristics and information literacy (PCIL); system and technological characteristics (STC); and organisational-process characteristics (OPC). The second-order factor PCIL includes four first-order factors: computer experience; computer self-efficacy; personal innovativeness toward IT; and computer anxiety. Second-order factor STC includes four first-order factors: ERP data quality; ERP system functionality; ERP system performance; and user manuals. Moreover, second-order factor OPC includes five first-order factors: organisational culture; fit with business processes, ERP training and education; ERP support; and ERP communication (Sternad \& Bobek, 2013; 2014; Sternad et al., 2011).

In ERP implementations, cognitive considerations besides PU and PEOU may become relevant (Nah et al., 2004). In the ERP context, organisations should adopt business processes of an implemented ERP system (Annamalai, \& Ramayah, 2013; Ju et al., 2016). Although one of the major benefits of ERP systems is that they offer organisations a solution based on best business practices, it is 
not necessary that this is also the best option for all ERP users. Inherent business rules behind the processes give them little choice but to follow protocols built into the ERP system (Sternad \& Bobek, 2013). Thus, organisations deploy ERP systems to facilitate organisational work rather than to match users' personal preferences or habits. Based on this understanding, we view work compatibility (WC) strictly as the fit of the ERP system to organisational work and not to personal preferences or work habits (Sun et al., 2009). WC is seen as the perception of fit between IT and work, which motivates employees to use the system, irrespective of actual fit (Sun et al., 2009). WC refers to the degree to which ERP users can do most of their tasks in the ERP system. WC influences PU, thereby demonstrating the importance of incorporating WC into models of IT usage, as explained in Sun et al. (2009) and Scott and Walczak (2009). In a context of ERP usage, the relationship between WC and PU is expected, i.e., the more work compatible the ERP system is, the more useful it is for ERP users. WC has a strong direct effect on AT, not just an indirect effect through PU; further, if ERP users believe that the ERP system is more compatible with their daily tasks, they will have a more positive attitude toward using the system (Sternad \& Bobek, 2013; 2014).

TAM was originally conceptualised in the context of personal use and ignored the role of organisational influences on IT/IS usage or its predictors (Sun et al., 2009). Organisational users use ERP systems to perform specific tasks and accelerate organisational work; because of that, it is important to examine the role of organisational work in ERP usage. ERP systems must be used by organisational workers where one user's tasks on the ERP system are tightly integrated with other users' tasks (Hsu et al., 2009; 2015; Isnalita, 2018; Nah et al., 2004; Rajan \& Baral, 2015). In other words, ERP users generally cannot choose whether or not to use the ERP system, regardless of their attitude. On the other hand, organisations that implement ERP systems want to use their systems to the fullest potential and realise the promised benefits. Thus, for organisations, it is important that ERP users go beyond the basics and utilise the extended functionality of the ERP system. Hsu et al. (2015) added that, although use is mandated, a content-valid and contextualised measure in this context must reflect user discretion and critical use behaviours. Hsieh and Wang (2007) defined extended use $(\mathrm{ExU})$ as the user behaviour that goes beyond typical usage and can lead to better results and returns. ExU captures the breadth and frequency of using different ERP features and functions (Hsu et al., 2015; Park et al., 2007; Sternad \& Bobek, 2014). If users find the ERP system to be useful, they will be more inclined to fully examine and use the system's features and functions (Saeed \& AbdinnourHelm, 2008); thus, actual use as specified in the original TAM has been replaced by ExU. Sternad and Bobek (2014) confirmed in their research that WC and AT impact ExU.

\section{Sample and Data Collection}

The first EU survey was carried out in 2010 (see Sternad $\&$ Bobek 2013; 2014). Because of relatively old data, we repeated the research study in the EU part in 2018. The new research revealed new insights, showing changes in competences and behaviour according to the use of ERP systems and advanced technologies; in addition, 444 questionnaires were properly filled out by respondents from 14 organisations, which have branches in more southeast European countries and used ERP solutions for daily operations longer than one year. Respondents were $39.9 \%$ male and $60.1 \%$ female (Table 1). Almost all of them had a high school education or more (except two respondents). More than half $(58.3 \%$; 259 respondents) indicated that they were workers (experts and other employees); others worked in low-level management (31.1\%, e.g., manager of the group or organisational unit), middle management (10\%, e.g., $\mathrm{CIO})$, and top management $(0.6 \%)$. The average of total working experience was 16.7 years, and an average of working experience at their current workplace was 8.2 years. Respondents had used an ERP system for 6.7 years, on average.

The research study in India was, for the first time, conducted in 2017; further, 577 questionnaires were properly filled out by respondents from 13 organisations and used for the analysis. Respondents were $73 \%$ male and $27 \%$ female (Table 1). Almost all of them had a high school education or more (except two respondents). Around one-third (35.5\%; 205 respondents) indicated they were workers (experts and other employees), $40.9 \%$ (236) indicated low management (e.g., manager of group or organisational unit), $20.8 \%$ (120) indicated middle management (e.g. CIO), and $2.8 \%$ (16) indicated top management. The average of total working years was 7.1, and the average of working years at the current workplace was 5.5. The ERP system had been used for 3.8 years on average.

Comparing the two researches' different but important socio-economic cultural backgrounds, it is notable to mention the huge age difference between the two researched samples. The EU sample shows an older respondent population, e.g., $60.1 \%$ of respondents were 40 years old or older. On the contrary, the India sample shows a younger respondent population, e.g., $80.9 \%$ of respondents were younger than 40 years. It is further established that the samples are also not comparable in terms of the sex of respondents, i.e., $60.1 \%$ of women responded to the EU sample, while $73.0 \%$ of men answered India's sample. Despite these facts, we did not give special attention to detected generation or gender differences. These could be one of the most important limitations of our research.

Demographic data were analysed by SPSS. All other empirical data were analysed in two-step analysis using the partial least squares (PLS) modelling technique, with the Smart PLS 3.2.1 method (Ringle et al., 2015). PLS path modelling is a variance-based structural equation modelling (SEM) technique, which has been widely used in business, social sciences, and education over the last 25 years (Garson, 2016; Henseler et al., 2016). In the first step, the measurement model was assessed; in the second step, the structural model. Path significance has been estimated using the bootstrapping resampling technique with 500 subsamples, as suggested by Ringle et al. (2015). While analysing data, we followed the guidelines specified by Henseler et al. (2016) and Garson (2016). 
Descriptive Statistics and Psychometric Properties of Measures $\left(n_{\mathrm{EU}}=444, n_{\text {India }}=577\right)$

\begin{tabular}{|c|c|c|c|c|c|}
\hline \multirow[b]{2}{*}{ Measure } & \multirow[b]{2}{*}{ Items } & \multicolumn{2}{|c|}{$\mathbf{E U}$} & \multicolumn{2}{|c|}{ India } \\
\hline & & Frequency & Percent & Frequency & Percent \\
\hline \multirow{2}{*}{ Gender } & Male & 177 & 39.9 & 421 & 73.0 \\
\hline & Female & 267 & 60.1 & 156 & 27.0 \\
\hline \multirow{6}{*}{ Age } & $<19$ & - & - & 26 & 4.5 \\
\hline & $20-29$ & 31 & 7.0 & 210 & 36.4 \\
\hline & $30-39$ & 146 & 32.9 & 230 & 40.0 \\
\hline & $40-49$ & 162 & 36.5 & 91 & 15.7 \\
\hline & $50-59$ & 102 & 23.0 & 20 & 3.4 \\
\hline & $60+$ & 3 & 0.6 & - & - \\
\hline \multirow{5}{*}{ Educational level } & Lower education & 2 & 0.5 & 2 & 0.4 \\
\hline & High school education & 152 & 34.2 & 24 & 4.2 \\
\hline & Bachelor education & 164 & 37.0 & 247 & 42.8 \\
\hline & Master education & 113 & 25.6 & 285 & 49.4 \\
\hline & Doctorate & 14 & 3.3 & 19 & 3.2 \\
\hline \multirow{4}{*}{ Working place } & Worker (experts and other employees) & 259 & 58.3 & 205 & 35.5 \\
\hline & $\begin{array}{l}\text { Low management (e.g. management of } \\
\text { group or organisational unit) }\end{array}$ & 138 & 31.1 & 236 & 40.9 \\
\hline & Middle management (e.g. CIO) & 44 & 10.0 & 120 & 20.8 \\
\hline & Top management & 3 & 0.6 & 16 & 2.8 \\
\hline
\end{tabular}

\section{Measurement Model}

All the scales were derived from previously developed and validated measures. The instrument's reliability was evaluated through the pilot testing. Psychometric properties (measurement model) of these scales were assessed via evaluation of reliability [measure of composite reliability (CR) which should exceed 0.70], convergent validity (measure of item factors loading, which should be significant and exceed 0.70 ), and the average variance extracted (AVE) for each construct (which should exceed 0.50), along with discriminant validity (square root of AVE for each construct, which should be higher than its correlation with any other latent factor), each of measurement scale. From EU model external factors experience with computer and computer selfefficacy from the PCIL group, ERP functionality and user manuals (help) from the STC group and ERP support, ERP communications and ERP training and education from OPC group were excluded (dotted rectangles in Figure 2) because they did not meet all the requirements of the measurement model. For the India model, external factors experience with computer and computer anxiety from PCIL group, user manuals (help) and ERP functionality from STC group and ERP support, ERP communications and ERP training and education from OPC group were excluded (dotted rectangles in Figure 3) because they did not meet all the requirements of the measurement model. The final version of the EU model and India model is presented. In Table 2, item means and loadings are presented followed by composite reliability (CR) and average variance extracted (AVE) for both models (EU and India). As shown in Table 2, each of 11 first-order factors in EU model and 11 first-order factors in the India model researched models had composite reliability (CR) exceeding 0.7 , assuring adequate reliability for our measurement scales. Further, all factors for both models exceed item factor loadings and the average variance extracted (AVE) values as the threshold of convergent validity as well. Also, the interconstruct correlation matrix for the EU and India model demonstrates that the discriminant validity of all scales for both models is adequate (results for this part of the methodology can be obtained by authors). Measurement results are satisfactory and suggest it is appropriate to proceed with the evaluation of the structural models.

Descriptive Statistics and Psychometric Properties of Measures $\left(n_{\mathrm{EU}}=444, n_{\text {India }}=577\right)$

Table 2

\begin{tabular}{|c|c|c|c|c|c|c|c|c|c|}
\hline \multirow[b]{2}{*}{ Construct } & \multirow[b]{2}{*}{ Indicators } & \multicolumn{4}{|c|}{ EU } & \multicolumn{4}{|c|}{ India } \\
\hline & & Item Means & Loadings & CR & AVE & Item Means & Loadings & CR & AVE \\
\hline \multirow{3}{*}{$\begin{array}{l}\text { Personal Innovativeness } \\
\text { Toward IT } \\
\text { (PI) }\end{array}$} & PCIL_PI1 & 3.68 & 0.96 & \multirow{3}{*}{0.95} & \multirow{3}{*}{0.91} & 4.59 & 0.88 & \multirow{3}{*}{0.87} & \multirow{3}{*}{0.77} \\
\hline & PCIL_PI2 & 3.13 & 0.94 & & & - & - & & \\
\hline & PCIL_PI3 & $5.57-$ & -0.10 & & & 4.67 & 0.87 & & \\
\hline \multirow{2}{*}{$\begin{array}{l}\text { Computer Self-Efficacy } \\
\text { (CS) }\end{array}$} & PCIL_SC1 & - & - & \multirow{2}{*}{ - } & \multirow{2}{*}{-} & 4.74 & 0.81 & \multirow{2}{*}{0.81} & \multirow{2}{*}{0.68} \\
\hline & PCIL_SC2 & - & - & & & 4.60 & 0.84 & & \\
\hline \multirow{3}{*}{$\begin{array}{l}\text { Computer Anxiety } \\
\text { (CA) }\end{array}$} & PCIL_CA1* & 4.66 & 0. & \multirow{3}{*}{0.0 .89} & \multirow{3}{*}{0.73} & - & - & \multirow{3}{*}{ - } & \multirow{3}{*}{ - } \\
\hline & PCIL_CA2* & 4.57 & 0. & & & - & - & & \\
\hline & PCIL_CA3 & 5.69 & 0.66 & & & - & - & & \\
\hline \multirow{6}{*}{$\begin{array}{l}\text { Data Quality } \\
\text { (DQ) }\end{array}$} & STC_DQ1 & 5.04 & 0.86 & \multirow{6}{*}{0.94} & \multirow{6}{*}{0.79} & 5.27 & 0.86 & \multirow{6}{*}{0.87} & \multirow{6}{*}{0.68} \\
\hline & STC_DQ2 & 5.09 & 0.91 & & & 5.38 & 8.84 & & \\
\hline & STC_DQ3 & 04.52 & 0.87 & & & - & - & & \\
\hline & STC_DQ4 & 5.00 & 0.91 & & & - & - & & \\
\hline & STC_DQ5 & - & - & & & - & - & & \\
\hline & STC_DQ6 & - & - & & & 5.23 & 0.78 & & \\
\hline
\end{tabular}


Simona Sternad Zabukovsek, Sangeeta Shah Bharadwaj, Samo Bobek, Tjasa Strukelj. Technology Acceptance Model...-

\begin{tabular}{|c|c|c|c|c|c|c|c|c|c|}
\hline \multirow[b]{2}{*}{ Construct } & \multirow[b]{2}{*}{ Indicators } & \multicolumn{4}{|c|}{ EU } & \multicolumn{4}{|c|}{ India } \\
\hline & & Item Means & \begin{tabular}{|l|} 
Loadings \\
\end{tabular} & CR & AVE & Item Means & \begin{tabular}{|l|} 
Loadings \\
\end{tabular} & CR & AVE \\
\hline \multirow{5}{*}{$\begin{array}{l}\text { System Performance } \\
\text { (SP) }\end{array}$} & STC_SP1 & 4.81 & 0.85 & \multirow{5}{*}{0.87} & \multirow{5}{*}{0.63} & 5.30 & 0.85 & \multirow{5}{*}{0.83} & \multirow{5}{*}{0.71} \\
\hline & STC_SP2 & 5.16 & 0.83 & & & 5.18 & 0.83 & & \\
\hline & STC_SP3 & 4.68 & 0.75 & & & - & - & & \\
\hline & STC_SP4 & - & - & & & - & - & & \\
\hline & STC_SP5 & 4.67 & 0.73 & & & - & - & & \\
\hline \multirow{4}{*}{$\begin{array}{l}\text { Business Processes Fit } \\
\text { (BPF) }\end{array}$} & OPC_BPF1 & 5.38 & 089 & \multirow{4}{*}{0.90} & \multirow{4}{*}{0.76} & 5.32 & 0.79 & \multirow{4}{*}{0.81} & \multirow{4}{*}{0.59} \\
\hline & OPC_BPF2 & 5.48 & 0.91 & & & 5.35 & 0.81 & & \\
\hline & OPC_BPF3 & - & - & & & - & - & & \\
\hline & OPCBPF4 & 5.49 & 0.81 & & & 4.60 & 0.70 & & \\
\hline \multirow{4}{*}{$\begin{array}{l}\text { Organisational culture } \\
\text { (OC) }\end{array}$} & OPC_OC1 & 5.28 & 0.89 & \multirow{4}{*}{0.90} & \multirow{4}{*}{0.74} & 5.18 & 0.86 & \multirow{4}{*}{0.85} & \multirow{4}{*}{0.65} \\
\hline & OPC_OC2 & 5,26 & 0.84 & & & 5.40 & 0.84 & & \\
\hline & OPC_OC3 & 5.10 & 0.85 & & & 5.21 & 0.73 & & \\
\hline & OPC_OC4 & - & - & & & - & - & & \\
\hline \multirow{5}{*}{$\begin{array}{l}\text { Perceived } \\
\text { usefulness } \\
\text { (PU) }\end{array}$} & PU1 & 4.92 & 0.93 & \multirow{5}{*}{0.89} & \multirow{5}{*}{0.81} & 5.27 & 0.81 & \multirow{5}{*}{0.88} & \multirow{5}{*}{0.59} \\
\hline & PU2 & 4.42 & 0.86 & & & 5.38 & 0.80 & & \\
\hline & PU3 & - & - & & & 5.45 & 0.77 & & \\
\hline & PU4 & - & - & & & 5.48 & 0.66 & & \\
\hline & PU5 & - & - & & & 5.27 & 0.79 & & \\
\hline \multirow{4}{*}{$\begin{array}{l}\text { Perceived ease of } \\
\text { use } \\
\text { (PEOU) }\end{array}$} & PEOU1 & 5.11 & 0.92 & \multirow{4}{*}{0.98} & \multirow{4}{*}{0.91} & 5.31 & 0.78 & \multirow{4}{*}{0.76} & \\
\hline & PEOU2 & 5.05 & 0.97 & & & 5.38 & 0.71 & & 0,52 \\
\hline & PEOU3 & 5.10 & 0.97 & & & - & - & & 0.52 \\
\hline & PEOU4 & 5.05 & 0.94 & & & 5.31 & 0.67 & & \\
\hline & WC1 & 4.60 & 0.89 & & & 5.24 & 0.77 & & \\
\hline Work compatibility & WC2 & 4.87 & 0.94 & 0.94 & 0.83 & 5.23 & 0.79 & 0.83 & 0.61 \\
\hline & WC3 & 4.99 & 0.90 & & & 5.28 & 0.78 & & \\
\hline Attitude toward use & AT1 & 5.80 & 0.91 & & & 5.41 & 0.87 & & \\
\hline (AT) & AT2 & 5.43 & 0.95 & 0.93 & 0.87 & 5.49 & 0.81 & 0.83 & 0.70 \\
\hline & ExU1 & 4.55 & 0.74 & & & 4.74 & 0.76 & & \\
\hline Extended use & ExU2 & 4.09 & 0.85 & 0.90 & 069 & 4.53 & 0.72 & 086 & 0.60 \\
\hline$(\mathbf{E x U})$ & ExU3 & 4.02 & 0.83 & 0.90 & 0.69 & 4.56 & 0.83 & 0.86 & 0.60 \\
\hline & ExU4 & - & - & & & 4.40 & 0.80 & & \\
\hline
\end{tabular}

\section{Structural Model}

In the research study, we examined the path significance. The results are based on bootstrapping (with 500 subsamples) to test the statistical significance of each path coefficient using t-tests, as recommended by Chin and Newsted (1999). Results of this analysis are shown in Figures 2 and 3, where rectangles represent factors and arrows the relationships between them. The upper coefficient along the arrows is the $\beta$-value; the lower coefficient in parentheses is the $t$-value.

Results of analysis for the extended TAM EU model are shown in Figure 2. PEOU has a statistically positive effect on PU $(\beta=0.23, p<0.01)$ and on AT $(\beta=0.36, p<0.05)$. PU has a very weak positive effect on AT $(\beta=0.11, p<0.01)$. WC has a statistically positive effect on $\mathrm{PU}(\beta=0.30, p<0.01)$, on AT $(\beta=0.37, p<0.01)$ and on $\operatorname{ExU}(\beta=0.38, p<0.01)$. AT has a statistically positive effect on $\operatorname{ExU}(\beta=0.20, p<0.01)$ in the EU model. Results of analysis for the extended TAM India model are shown in Figure 3. PEOU has a very weak positive effect on PU $(\beta=0.12, p<0.01)$ and an even weaker but significant effect on AT $(\beta=0.11, p<0.05)$. PU has a statistically positive effect on AT $(\beta=0.39, p<0.01)$. WC has a very weak positive effect on PU $(\beta=0.14, p<0.01)$ and a weak positive effect on $\operatorname{AT~}(\beta=0.22, p<0.01)$ statistically positive effect and on ExU $(\beta=0.34, p<0.01)$. AT has no statistically effect on ExU $(\beta=0.05, p>0.05)$ in the India model.
From Figures 2 and 3, we can recognise differences in the models. We calculated differences in strength and relative importance of individual relationships among observed factors in the EU and India extended TAM models (Table 3), as suggested by Koch (2014). The relationships in the EU and India models for four relationships demonstrate distinct differences: PEOU on AT $(t=6.40, p<0.01)$; PU on AT $(t=-$ 1.99, $p<0.05)$; WC on AT $(t=1.94, p<0.05)$; and WC on PU $(t=2.09, p<0.05)$. The important result of our research is that there are significant differences regarding the strength and relative importance of individual relationships among them except three relationships (between AT and ExU, PEOU and $\mathrm{PU}$, and $\mathrm{WC}$ and ExU). Almost all relationships have a stronger statistical effect in the EU model, as in the India model, except influence of PU on AT and WC on ExU, which has a stronger statistical effect in India than in the EU model (see column $\beta_{\mathrm{EU}}-\beta_{\text {India }}$ in Table 3 ). We did not research differences in strength and relative importance of individual relationships of external factors on the extended model TAM because not all factors from the research model are included in both models (see Table 2). 
Significance of Estimated Coefficients and Differences between the EU and India Model

\begin{tabular}{|c|c|c|c|c|c|c|}
\hline & \multicolumn{2}{|c|}{$\mathbf{E U}$} & \multicolumn{2}{|c|}{ India } & \multicolumn{2}{|c|}{ Differences between the EU and India model } \\
\hline & $\beta$-value & Standard error & $\beta$-value & Standard error & $\beta_{\text {EU }}-\beta_{\text {India }}$ & $t$-value \\
\hline $\mathrm{AT} \rightarrow \mathrm{ExU}$ & $0.20 * *$ & 0.06 & $0.05^{\text {n.s. }}$ & 0.05 & 0.15 & $1.94^{\text {n.s. }}$ \\
\hline $\mathrm{PEOU} \rightarrow \mathrm{AT}$ & $0.57 * *$ & 0.05 & $0.11 *$ & 0.05 & 0.46 & $6.40 * *$ \\
\hline $\mathrm{PEOU} \rightarrow \mathrm{PU}$ & $0.23 * *$ & 0.07 & $0.12 * *$ & 0.03 & 0.11 & $1.57^{\text {n.s. }}$ \\
\hline $\mathrm{PU} \rightarrow \mathrm{AT}$ & $0.21 * *$ & 0.08 & $0.39 * *$ & 0.05 & -0.18 & $-1.99 *$ \\
\hline $\mathrm{WC} \rightarrow \mathrm{AT}$ & $0.37 * *$ & 0.06 & $0.22 * *$ & 0.05 & 0.15 & $1.94 *$ \\
\hline $\mathrm{WC} \rightarrow \mathrm{PU}$ & $0.30 * *$ & 0.07 & $0.14^{* *}$ & 0.04 & 0.16 & $2.09 *$ \\
\hline $\mathrm{WC} \rightarrow \mathrm{ExU}$ & $0.38 * *$ & 0.05 & $0.34^{* *}$ & 0.05 & 0.04 & $0.56^{\text {n.s. }}$ \\
\hline
\end{tabular}

Note: $* * p<0.01, * p<0.05$, ${ }^{\text {n.s. }}$ not significant.

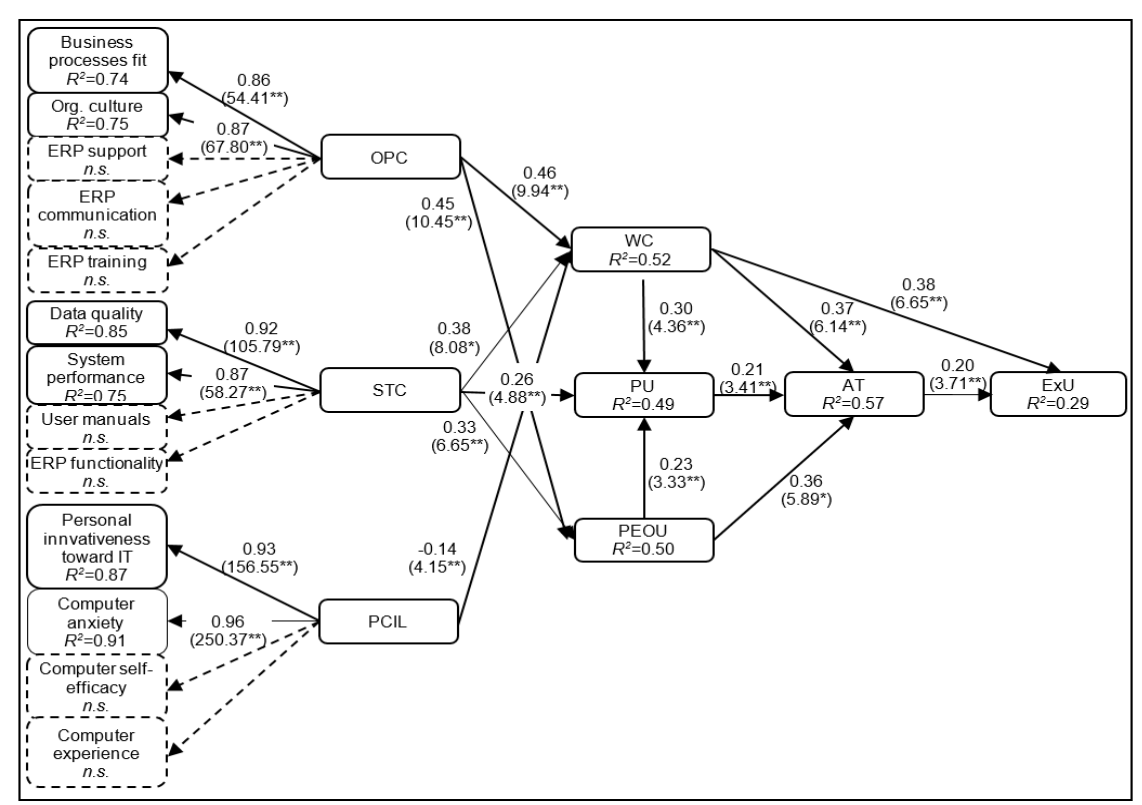

Figure 2. Results of Structural Model Analysis EU ${ }^{\mathrm{a}, \mathrm{b}}$

a The upper coefficient along the arrows is the $\beta$-value; the lower coefficient in parentheses is the t-value. $b$ Path significance: $* * p<0.01, * p<0.05$, n.s. $=$ not significant (shapes are marked dotted).

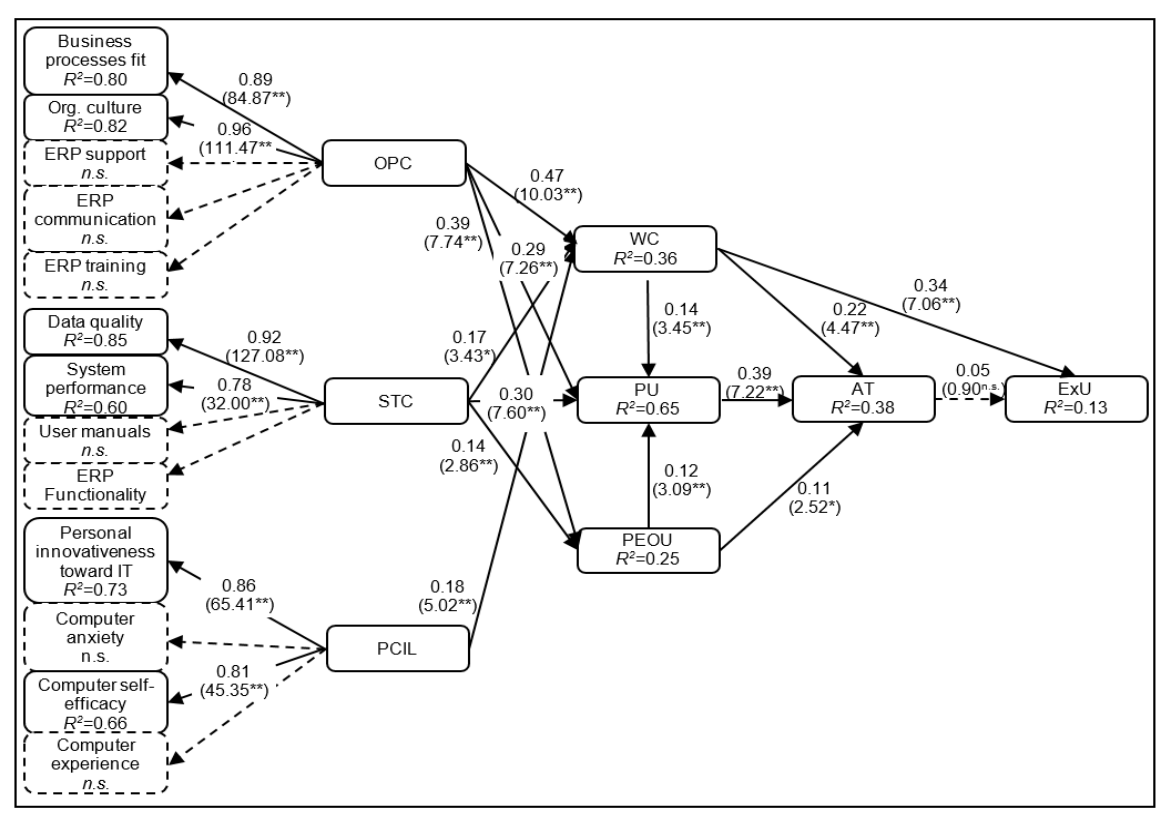

Figure 3. Results of Structural Model Analysis India ${ }^{a, b}$

a The upper coefficient along the arrows is the $\beta$-value; the lower coefficient in parentheses is the $t$-value. $b$ Path significance: $* * p<0.01$, $*<<0.05$, n.s. = not significant (shapes are marked dotted). 
Overall effect size measure for the structural model is $R^{2}$, also called the coefficient of determination (Garson, 2016). The structural model for the EU demonstrates predictive power as the variance explained $\left(R^{2}\right)$ in key endogenous constructs and is 0.52 for WC, 0.49 for PU, 0.50 for PEOU, 0.57 for AT and 0.29 for ExU (see $R^{2}$ numbers inside rectangles in Figure 2). All $R^{2}$ can be described as "moderate" by Chin (1998), except ExU, which can be described as "weak," although the researched factors explain almost $30 \%$ of influence on the ExU of the implemented IT/IS system. The findings show that our model explains a large part of the variance in the endogenous factors, with an average $R^{2}$ of 0.47. The structural model for India also demonstrates predictive power in key endogenous constructs and is 0.36 for WC, 0.65 for PU, 0.25 for PEOU, 0.38 for AT, 0.13 for ExU (see $R^{2}$ numbers inside rectangles in Figure 3 ). WC, PU, and AT have moderate overall effect size; PEOU and ExU have week overall model effect. The India model explains the not so large part of the variance in endogenous factors as the EU model, with an average $R^{2}$ of 0.35 .

As part of the model, evaluation is the examination of fit indexes reflecting the predictive power of estimated inner and outer model relationships, which can be measured by evaluating goodness-of-fit $(G o F)$ coefficient (Tenenhaus et $a l ., 2005)$. The general criterion for evaluating $G o F$ is to calculate the geometric mean of the average $A V E$ s and the average $R^{2}$ for the inner model (Henseler et al., 2012). Based on categorisation by Cohen (1998), GoF criteria for small, medium, and large effect sizes would be $0.1,0.25$, and 0.36 , respectively. Although the use of $G o F$ is lately disparaged due to various statistical shortcomings (Garson, 2016), Henseler, Ringle, and Sarstedt (2012) note that GoF may still be useful in assessing $G o F$, which data sets better explain PLS than do others, with higher reflecting better explanation. For the EU model, GoF is 0.69; for the India model, GoF is 0.45 . Both GoFs indicate large fit of the models to the data, where data sets from the EU model better explain the model.

\section{Discussion}

When the results of data collected from the EU and India are compared, differences emerge. These differences help organisations' managers to understand which factors, and to what extent, have an impact on ERP acceptance and utilisation. Therefore, the economic aspect of this study, which results in the organisation's efficiency and effectiveness, should also be highlighted. Organisations that understand which factors influence ERP users' satisfaction can influence users' extended use (ExU) of the ERP system and thus attain organisations' better results and returns (Hsieh \& Wang, 2007; Hsu et al., 2015; Sternad \& Bobek, 2014). This differs in different cultural environments (Annamalai \& Ramayah, 2013; Hancerliogullari Koksalmis \& Damar, 2019; Isnalita, 2018; Krumbholz et al., 2000; Leidner \& Kayworth, 2006; Rajan \& Baral, 2015; Scholtz, Mahmud \& Ramayah, 2016; Stuart et al., 2010).

In the EU and India data, all three factors: WC, PEOU, and PU significantly impact AT, which is consistent with some other research in ERP settings (Nah et al., 2004; Sternad \& Bobek, 2013; 2014). The EU and India data also show a statistically significant positive influence of PEOU on PU, but the influence is more important in the $\mathrm{EU}(\beta=0.23)$ as in India $(\beta=0.12$; see Table 3$)$. These findings are consistent with research in ERP settings, which supports a relationship between PEOU and PU (Amoako-Gyampah \& Salam, 2004; Bueno \& Salmeron, 2008; Calisir et al., 2009; Costa et al., 2016; Hancerliogullari Koksalmis \& Damar, 2019; Hsieh \& Wang, 2007; Isnalita, 2018; Mayeh et al., 2016; Rajan \& Baral, 2015). Some authors argue that PEOU appears to be more important during phases of implementation and is becoming less important over time of use (Davis et al., 1989; Nah et al., 2004).

In the EU and India data, the WC factor has a significant impact on PU, in the EU much stronger $(\beta=0.30)$ as in India $(\beta=0.14$; see Table 3$)$. WC also has a significant impact on $\mathrm{AT}$ and ExU in both models. If we combine this finding with results regarding the impact of AT to ExU (where in India, AT had no significant effect on ExU and in the EU, the impact of AT on ExU was significant), we might speculate that there is a different pattern of how users actually use ERP systems to support their daily tasks. The difference in organisational culture between the EU and India is noted in several studies (Annamalai \& Ramayah, 2013; Leidner \& Kayworth, 2006; Rajan \& Baral, 2015; Stuart et al., 2010). According to Recht and Wilderom (1998), IT/IS use is confronted with different organisational cultures. Because of this, the perception of PU and the way how end-users actually use ERP (ExU) could be different in different cultural environments (Annamalai \& Ramayah, 2013). Some authors report that Indian culture is more authoritative instead of participative where ExU gains on importance (Krumbholz et al., 2000; Rajapakse \& Seddon, 2017). This cultural difference between the EU and India might be the reason for explaining that AT has a positive, statistically significant impact on ExU in the researched EU sample but has no statistically significant influence in the researched India sample.

Influence of PU on AT supports research in ERP settings (see Bueno \& Salmeron, 2008; Nah et al., 2004; Sternad \& Bobek, 2013; 2014; Sternad et al., 2011). PU in the researched India model has a significant effect on AT, as it does in the researched EU model, too; although, the latter is much weaker. It appears that users in India better adapt their work to the ERP system. These conclusions are in line with studies researching the impact of national and organisational culture on ERP implementation and use. Annamalai and Ramayah (2013), for example, found that the level of perceived ERP benefits did not significantly affect ERP implementation success in a sample of organisations in India. The authors demonstrate that culture moderates the relationship of key success factors and implementation success and that, in India culture, appears to emphasise a hierarchical management style that emphasises top-down implementation with less attention given to worker acceptance. Other studies in India emphasise managerial elements of implementation over user characteristics such as PU and AT (Kale et al., 2010). However, it should be recognized that management style and organisational culture are as diverse in India as they are elsewhere. ERP systems themselves reflect their cultures of origin in how they are structured, and this, too, can create cultural gaps when implemented elsewhere (Alhirz \& Sajeev, 2015; Kwahk \& Ahn, 2010). 
From the PCIL group in both researched models, personal innovativeness toward IT is an important external factor. ERP solutions are complex; therefore, personal innovativeness is expected to be important so users can cope with complex functionality. This research shows that users in the EU are concerned about computer anxiety because they are aware of the complexity of ERP solutions and of the importance of ERP use (Venkatesh \& Davis, 2000). In India, this research shows the importance of computer selfefficiency instead, which is consistent with other research (Amoako-Gyampah \& Salam, 2004; Isnalita, 2018; Rajan \& Baral, 2015; Venkatesh \& Davis, 2000). The second-order factor PCIL has a negative impact on WC in the EU model, while the impact on PU and PEOU is not statistically significant. Data can be obtained from the authors. This is not consistent with Sternad et al.'s (2011) research, which demonstrated that PCIL has a weak positive impact on PEOU and does not have an impact on PU and WC. On the contrary, second-order factor PCIL through first-order factors personal innovativeness toward IT and computer self-efficacy have a positive impact on PU in the India model, while impacts on WC and PEOU are not statistically significant. Also, these data can be gained from authors. Opposite, Rajan and Baral (2015) in their research in India revealed that computer self-efficacy has a positive statistically significant effect on PU and PEOU.

The STC group is in both researched models' data quality a most important external factor, followed by system performance. These two factors were researched as important external factors by different authors (Amoako-Gyampah \& Salam, 2004; Bradford, 2008; Bueno \& Salmeron, 2008; Calisir et al., 2009; Nah et al., 2004; Sternad \& Bobek, 2013; Sternad et al. 2011). In both models, the second-order factor STC has a positive impact on PEOU, PU, and WC. These three relationships are more important in the EU model, where STC has a weak impact on PEOU and WC, while in the India model both relationships have an even weaker impact. In the India model, there is a weak relationship between the STC and PU, while in the EU model this relationship is even weaker.

From the OPC group, both models fit with business processes, and organisational culture is important. The EU sample shows that, for ERP users, the most important ERP solution is ease of use (PEOU; $\beta=0.45$; see Figure 2 ) and that it fits their organisational work (WC; $\beta=0.46$; see Figure 2). While the India sample shows that, for ERP users, most important is that ERP solution fits their organisational work (WC; $\beta=0.47$; see Figure 3 ), followed by ERP solution ease of use (PEOU; $\beta=0.39$; see Figure 3 ); further, usefulness of ERP (PU; $\beta=0.29$; see Figure 3 ) is important. Business process fit and organisational culture are important in both models. These findings are consistent with other research results (AmoakoGyampah \& Salam, 2004; Bradford, 2008; Calisir et al., 2009; Nah et al., 2004; Sternad \& Bobek, 2013; Sternad et al., 2011; Umble et al., 2002). OPC has a moderate impact on WC in both models. It also has a weak positive effect on PU in India, but this relationship is not statistically significant in the EU model (data can be gained from authors). OPC also has a moderate effect on PEOU in both models. In addition, from both models, it can be observed that ERP support, communication, and training are not important for ERP users in the maturity stage researched, which differs from previous researches (AmoakoGyampah \& Salam, 2004; Costa et al., 2016; Isnalita, 2018; Rajan \& Baral, 2015).

\section{Conclusion}

The adoption of enterprise resource planning (ERP) systems by organisations is crucial in today's competitive globalised marketplace. The experience with ERP systems in numerous organisations over the last decade indicates that successful implementation of ERP systems does not necessarily lead to successful ERP usage. Namely, organisations benefit from ERP systems only to the extent to which the users accept and utilise them. But the use of ERP systems at an advanced level is closely connected with the employees' acceptance of these systems. To improve the efficiency and effectiveness of ERP systems in their maturity stage of use (when the employees already accepted ERP system), organisations need to understand the factors that have an impact on user satisfaction and thus influence their extended use of the ERP system. We conducted a comparative research study into the similarities and differences of their use of ERP systems in the EU and India. There are differences connected to organisational cultures, presumed resulting from cultural differences of researched regions.

This study identified factors leading users to better use their ERP solutions. We combined Sternad et al. (2011) and Sternad and Bobek $(2013 ; 2014)$ models and the expanded basic TAM model with more generic contextual factors and examined their influence in perceived ERP usefulness (PU) and perceived ease of use (PEOU). Researching the influence of external factors on constructs not only contributes to the theory development but also helps in understanding potential cultural differences and helps in designing interventional programs for organisations.

We can confirm the research question that ERP system acceptance and its extended use can be measured with the same factors in different cultural environments. The comparison of the EU and India sample in this research demonstrates similarities between both samples, with only a few impacts differing in significance (see Table 3 ). The existing differences affect components significantly, thus suggesting that differences may exist between the EU and India in ERP utilisation. Sample sizes are not large enough to generalise results to the two regions, but the results are provocative. Although the results are statistically relevant, further research with larger territorial scope will increase the model's explanatory capabilities. Ongoing research will attempt to conduct more cross-cultural comparisons to further test and develop the research model and further research the cultural factors affecting IT/IS management, as suggested by researchers (Mayeh et al., 2016). Moohebat et al.'s (2010) research also showed that ERP implementation's critical success factors are not much different in developed and developing countries, although there are still undeniable differences. The authors added that it seems that the national culture of developing countries has an impressive effect on ERP implementation in these countries.

On the other hand, organisations in developing countries depend more on ERP vendors in comparison with organisations in developed countries. Also, developing countries underestimate business process reengineering and fit between ERP and business/process factors. Mentioned authors revealed that cultural issues are important factors that differentiate developed and developing countries in ERP implementation. 
This research aimed to improve the understanding of how 13 external factors have an impact on the degree of the AT and consequently improve the ExU. This work combines previous research by incorporating groups of external factors, as suggested by Sternad et al. (2011) and Sternad and Bobek (2013): personal innovativeness toward IT, computer anxiety, self-efficacy, and computer experience as a conceptual factor of PCIL; data quality, system performance, user manuals, and ERP functionality as a conceptual factor of STC; and business processes fit, organisational culture, ERP support, ERP communication, and ERP training as a conceptual factor of OPC. These three conceptual factors influence perceived ease of use (PEOU), perceived usefulness (PU), and work compatibility (WC), which further influence attitude toward using ERP solutions (AT) and extended use of ERP solutions (ExU). The findings extend the ERP literature and practice by viewing the success of a mandated system from the users' perspective. Namely, it is important to know that users' extensive and explorative use of the ERP system (ExU) yields successful ERP system outcomes at the organisational level (Hsu et al., 2009).

From a theoretical point of view, the present work extends the original TAM model (Davis, 1989; Davis et al., 1989). In addition to the original TAM factors, an additional factor work compatibility (WC) presented by Sun et al. (2009) is important for explaining users' behaviour in ERP contexts. Sun et al. (2009) explain the importance of work compatibility (WC) on perceived usefulness (PU) and behavioural intention to use in ERP settings. The relationship between work compatibility (WC) and attitude toward using IT (AT) is statistically proven by Sternad and Bobek (2013; 2014). The authors also validated the relationship between work compatibility (WC) and attitude toward using IT (AT) on the extended use of IT (ExU). For readers, the presented model can be useful in increasing their understanding of the complexity and areas of concern regarding the ERP system used in the EU and in India.

Important limitations of the article are derived from the selection of the EU countries sample. The survey was carried out only in selected southeast EU countries, in which, for a more realistic picture, it would be sensible to increase the sample size. In the future, we propose to include other EU countries in the sample. In this way, researchers would gain a larger geographical sample and thus more realistic data for the EU. It would also be sensible to check statistically signification of differences between the "old" and "new" EU countries. A larger sample for more realistic findings would also make sense in India.

For further research directions, we recommend a longitudinal approach, which will help researchers to understand how the factors vary at different stages of usage of ERP. We also recommend exploring the interrelationships among groups of external factors (PCIL, STC, and OPC) and their direct effect on extended use of ERP system implemented (ExU).

It would be worthwhile to direct future research into a comparison between micro-, small, and medium-size and large companies. This would be sensible to research, as ERP solutions are increasingly penetrating SME organisations. In this article, the authors have not done this, which represents a significant limitation. Because smaller enterprises have different characteristics than larger ones, it is assumed that they also differ in the view of the subject matter studied. Significant differences can also occur within size classes among SMEs.

An important limitation is also the fact that, in the article, the authors did not study the differences between respondents' answers regarding the vendor (provider) of the ERP solution. Because significant differences in findings could also arise from this point of view, this represents not only a limitation but also a possibility for further research.

At last, but not least, it is necessary to underline the fact that, in the studied samples, the respondents differ significantly regarding age and gender. In the EU sample, a significantly older population responded than in the sample of India, which is consistent with the age structure of the geographical areas studied but may also be an important factor in the differences in results. Therefore, also from this point of view, this article is limited, which at the same time represents a possible area for further research.

\section{References}

Ajzen, I. (1991). The Theory of Planned Behavior. Organizational Behavior and Human Decision Processes, 50, $179-211$. https://doi.org/10.1016/0749-5978(91)90020-T

Alhadi, M., \& Al-Shaibany, N. (2017). An Extended ERP model for Yemeni universities using TAM model. International Journal Of Engineering And Computer Science, 6, 22084-22096. https://doi.org/10.18535/ijecs/v6i7.31.

Alhirz, H., \& Sajeev, A. S. M. (2015). Do cultural dimensions differentiate ERP acceptance? A study in the context of Saudi Arabia. Information Technology \& People, 28(1), 163-194. https://doi.org/10.1108/ITP-07-2013-0127

Amoako-Gyampah, K., \& Salam, A. F. (2004). An extension of the technology acceptance model in an ERP implementation environment. Information \& Management, 41, 731-745. https://doi.org/10.1016/j.im.2003.08.010

Annamalai, C., \& Ramayah, T. (2013). Does the Organizational Culture Act as a Moderator in Indian Enterprise Resource Planning (ERP) Projects? An Empirical Study. Journal of Manufacturing Technology Management, 24, $555-587$. https://doi.org/10.1108/17410381311327404

Bazhair, A., \& Sandhu, K. (2015). Factors for the Acceptance of Enterprise Resource Planning ( ERP ) Systems and Financial Performance. Journal of Economics, Business and Management, 3(1), 1-10. https://doi.org/10.7763/ JOEBM.2015.V3.146 
Bradford, M. (2008). Modern ERP - Select, implement \& use today's advanced business systems. Raleigh: College of Management, North Carolina State University.

Bradley, J., \& Lee, C. C. (2007). ERP training and user satisfaction: A case study. International Journal of Enterprise Information Systems, 3(4), 33-50. https://doi.org/10.4018/jeis.2007100103

Bueno, S., \& Salmeron, J. L. (2008). TAM-based success modelling in ERP. Interacting with Computers, 20(6), 515-523. https://doi.org/10.1016/j.intcom.2008.08.003

Calisir, F., Gumussoy, C. A., \& Bayram, A. (2009). Predicting the behavioural intention to use enterprise resource planning systems - An exploratory extension of the technology acceptance model. Management Research News, 32(7), 597613. https://doi.org/10.1108/01409170910965215

Chin, W. W., \& Newsted, P. R. (1999). Structural Equation Modelling Analysis with Small Samples using Partial Least Squares. In R. H Hoyle (Ed.), Statistical Strategies for Small Sample Research (pp. 307-341). Thousand Oaks, CA: SAGE.

Cohen, J. (1988). Statistical power analysis for the behavioral sciences (2nd ed.). Hillsdale, NJ: Lawrence Erlbaum Associates.

Costa, C., Ferreira, E., Bento, F., \& Aparicio, A. (2016). Enterprise resource planning adoption and satisfaction determinants. Computers in Human Behaviour, 63, 659-671. https://doi.org/10.1016/j.chb.2016.05.090

Davis, F. D. (1989). Perceived Usefulness, Perceived Ease of Use, and User Acceptance of Information Technology. MIS Quarterly, 13(3), 319-340. https://doi.org/10.1287/mnsc.35.8.982

Davis, F. D., Bagozzi, R. P., \& Warshaw, P. R. (1989). User acceptance of computer technology: A comparison of two theoretical models. Management Science, 35(8), 982-1003. https://doi.org/10.2307/249008

Fishbein, M., \& Ajzen, I. (1975). Belief, Attitude, Intention, and Behavior: An Introduction to Theory and Research. Reading, MA: Addison-Wesley.

Garson, G. D. (2016). Partial Least Squares: Regression and Structural Equation Models. Asheboro, NC: Statistical Associates Publishers.

Habjan, N., Hovelja, T., \& Vaupotic, D. (2016). Evaluating ERP as a composition of different functionalities from key stakeholder perspectives. In S. Kowalski, P. Bednar \& I. Bider (Eds.), Proceedings of STPIS'16 (14 pgs.). Available from internet: http://ceur-ws.org/Vol-1604/Paper1.pdf (May 20, 2016).

Hancerliogullari Koksalmis G., \& Damar S. (2019). Exploring the Adoption of ERP Systems: An Empirical Investigation of End-Users in an Emerging Country. In: Calisir F., Cevikcan E., Camgoz Akdag H. (eds.) Industrial Engineering in the Big Data Era (pp. 307-318). Lecture Notes in Management and Industrial Engineering. Springer, Cham. https://doi.org/10.1007/978-3-030-03317-0_26

Henseler, J., Hubona, G., \& Ray, P. A. (2016). Using PLS Path Modeling in New Technology Research: Updated Guidelines. Industrial Management \& Data Systems, 116(1), 2-20. https://doi.org/10.1108/IMDS-09-2015-0382

Henseler, J., Ringle, C. M., \& Sarstedt, M. (2012). Using Partial Least Squares Path Modelling in International Advertising Research: Basic Concepts and Recent Issues. In S. Okzaki (Ed.), Handbook in Partial Least Squares: Concepts, Methods and Applications in Marketing and Related Fields (pp. 252-276). Berlin: Springer.

Hsieh, J. J. P. A., \& Wang, W. (2007). Explaining Employees' Extended Use of Complex Information Systems. European Journal of Information Systems, 16(3), 216-227. https://doi.org/10.1057/palgrave.ejis.3000663

Hsu, M. K., Wang, S. W., \& Chin, K. K. (2009). Computer Attitude, Statistics Anxiety and Self-efficacy on Statistical Software Adoption Behavior: An Empirical Study of Online MBA learners. Computers in Human Behavior, 25(2), 412-420. https://doi.org/10.1016/j.chb.2008.10.003

Hsu, P. F., Yen, H. R., \& Chung, J. C. (2015). Assessing ERP Post-implementation Success at the Individual Level: Revisiting the Role of Service Quality. Information \& Management, 52(8), 925-942. https://doi.org/10.1016/ j.im.2015.06.009

Huang, T., \& Yasuda, K. (2016). Comprehensive review of literature survey articles on ERP. Business Process Management Journal, 22(1), 2-32. https://doi.org/10.1108/BPMJ-12-2014-0122

Isnalita, S. N. A. (2018). ERP system adoption determinants. Jurnal Riset Akuntansi dan Bisnis Airlangga, 3 (2), 470-480. https://doi.org/10.31093/jraba.v3i2.124

Ju, P. H., Wei, H. L., \& Tsai, C. C. (2016). Model of Post-Implementation User Participation within ERP Advice Network. Asia Pacific Management Review, 21(2), 92-101. https://doi.org/10.1016/j.apmrv.2015.11.001 
Simona Sternad Zabukovsek, Sangeeta Shah Bharadwaj, Samo Bobek, Tjasa Strukelj. Technology Acceptance Model...-

Kale, P. T, Banwait, S. S., \& Laroiya, S. C. (2010). Performance Evaluation of ERP Implementation in Indian SMEs. Journal of Manufacturing Technology Management, 21(6), 758-780. https://doi.org/10.1108/17410381011064030

Koch, N. (2014). Advanced mediating effects tests, multi-group analyses, and measurement model assessments in PLSbased SEM. International Journal of e-Collaboration, 10(1), 1-13. https://doi.org/10.4018/ijec.2014010101

Krumbholz, M., Galliers, J., Coulianos, N., \& Maiden, N. A. M. (2000). Implementing Enterprise Resource Planning Packages in Different Corporate and National Cultures. Journal of Information Technology, 15, $267-279$. https://doi.org/10.1016/S0306-4379(01)00016-3

Kwahk, K. Y., \& Ahn, H. (2010). Moderating Effects of Localization Differences on ERP Use: A Socio-technical Systems Perspective. Computers in Human Behavior, 26, 186-198. https://doi.org/10.1016/j.chb.2009.10.006

Kwahk, K. Y., \& Lee, J. N. (2008). The Role of Readiness for Change in ERP Implementation: Theoretical Bases and Empirical Validation. Information \& Management, 45(7), 474-481. https://doi.org/10.1016/j.im.2008.07.002

Lee, D. H., Lee, S. M., Olson, d. L., \& Chung, S. H. (2010). The Effect of Organizational Support on ERP Implementation. Industrial Management \& Data Systems, 110(2), 269-283. https://doi.org/10.1108/02635571011020340

Leidner, D.E., \& Kayworth, T. (2006). A Review of Culture in Information Systems Research: Toward a Theory of Information Technology Culture Conflict. MIS Quarterly, 30(2), 357-399. https://doi.org/10.2307/25148735

Mayeh, M., Ramayah, T., \& Mishra, A. (2016). The Role of Absorptive Capacity, Communication and Trust in ERP Adoption. The Journal of Systems and Software, 119, 58-69. https://doi.org/10.1016/j.jss.2016.05.025

Moohebat, M. R., Asemi, A., \& Jazi, M. D. (2010). A comparative study of critical success factors (CSFs) in implementation of ERP in developed and developing countries. International Journal of Advancements in Computing Technology, 2(5), 99-110. https://doi.org/10.4156/ijact.vol2.issue5.11

Nah, F. F., Tan, X., \& Teh, S. H. (2004). An Empirical Investigation on End-Users' Acceptance of Enterprise Systems. Information Resources Management Journal, 17(3), 32-53. https://doi.org/10.4018/irmj.2004070103

Panorama. (2010). Break on Through to the Other Side: Moving Beyond ERP "Go-Live" to Competitive Edge and ROI. Available from internet: https://www.panorama-consulting.com/break-on-through-to-the-other-side-moving-beyonderp-go-live-to-competitive-edge-and-roi/(December 4, 2018).

Park, J. H., Suh, H. J., \& Yang, H. D. (2007). Perceived Absorptive Capacity of Individual Users in Performance of Enterprise Resource Planning (ERP) Usage: The Case for Korean firms. Information \& Management, 44(3), 300-312. https://doi.org/10.1016/j.im.2007.02.001

Rajan, C. A., \& Baral, R. (2015). Adoption of ERP system: An empirical study of factors influencing the usage of ERP and its impact on end user. IIMB Management Review, 27(2), 105-117. https://doi.org/10.1016/j.iimb.2015.04.008

Rajapakse, J., \& Seddon, P. B. (2005). ERP Adoption in Developing Countries in Asia: A Cultural Misfit. Available from internet: www.hia.no/iris28/Docs/IRIS2028-1028.pdf (September 2, 2017).

Recht, R., \& Wilderom, C. (1998). Kaizen and Culture: on the Transferability of Japanese Suggestion Systems. International Business Review, 7, 7-22. https://doi.org/10.1016/S0969-5931(97)00048-6

Ringle, C. M., Wende, S., and Becker, J. M. (2015). SmartPLS 3. Boenningstedt: SmartPLS GmbH. Available from internet: http://www.smartpls.com (December 17, 2018).

Saeed, K. A., \& Abdinnour-Helm, S. (2008). Examining the Effects of Information System Characteristics and Perceived Usefulness on Post Adoption Usage of Information Systems. Information and Management, 45(6), 376-386. https://doi.org/10.1016/j.im.2008.06.002

Schlichter, B. R., \& Kraemmergaard, P. (2010). A comprehensive literature review of the ERP research field over a decade. Journal of Enterprise Information Management, 23(4), 486-520. https://doi.org/10.1108/17410391011061780

Scholtz, B., Mahmud, I., \& Ramayah, T. (2016). Does usability matter? An analysis of the impact of usability on technology acceptance in ERP settings. Interdisciplinary Journal of Information, Knowledge, and Management, 11, 309-330. https://doi.org/10.28945/3591

Scott, J. E., \& Walczak, S. (2009). Cognitive Engagement with a Multimedia ERP Training Tool: Assessing Computer Self-Efficacy and Technology Acceptance. Information \& Management, 46(4), 221-232. https://doi.org/10. 1016/j.im.2008.10.003

Sternad, S., \& Bobek, S. (2013). TAM-Based External Factors Related to ERP Solutions Acceptance in Organizations. International Journal of Information Systems and Project Management, 1(4), 25-38. https://doi.org/10.1016/ j.protcy.2013.12.004 
Sternad, S., \& Bobek, S. (2014). ERP Business Solutions Acceptance in Companies. In S. R. Chatterjee (Ed.), Managing in recovering markets (pp. 283-294). New Delhi [etc.]: Springer. https://doi.org/10.1007/978-81-322-1979-8_22

Sternad, S., Gradisar, M., \& Bobek, S. (2011). The Influence of External Factors on Routine ERP Usage. Industrial management + data systems, 111(9), 1511-1530. https://doi.org/10.1108/02635571111182818

Stuart, L., Mills, A., \& Remus, U. (2010). The Influence of Organizational Culture Across the Stages of Enterprise System Implementations. In PACIS 2010 Proceedings, 194. Available from internet: http://aisel.aisnet.org/pacis2010/194 (April 13, 2018).

Sun, Y., Bhattacherjee, A., \& Ma, Q. (2009). Extending Technology Usage to Work Settings: The Role of Perceived Work Compatibility in ERP Implementation. Information \& Management, 46(6), 351-356. https://doi.org/10.1016/j. im.2009.06.003

Turner, M., Kitchenham, B., Brereton, P., Charters, S., \& Budgen, D. (2010). Does the Technology Acceptance Model Predict Actual Use? A Systematic Literature Review. Information and Software Technology, 52, $463-479$. https://doi.org/10.1016/j.infsof.2009.11.005

Umble, E. J., Haft, R. R., \& Umble, M. M. (2002). Enterprise Resource Planning: Implementation Procedures and CSF. European Journal of Operational Research, 146(2), 241-257. https://doi.org/10.1016/S0377-2217(02)00547-7

Uzoka, F. M. E., Abiola, R. O., \& Nyangeresi, R. (2008). Influence of Product and Organizational Constructs on ERP Acquisition Using an Extended Technology Acceptance Model. International Journal of Enterprise Information Systems, 4(2), 67-83. https://doi.org/10.4018/jeis.2008040105

Venkatesh, V., \& Bala, H. (2008). Technology acceptance model 3 and a research agenda on interventions. Decision Sciences, 39(2), 273-315. https://doi.org/10.1111/j.1540-5915.2008.00192.x

Venkatesh, V., \& Davis, F. D. (2000). A Theoretical Extension of the Technology Acceptance Model: Four Longitudinal Field Studies. Management Science, 46(2), 186-205. https://doi.org/10.1287/mnsc.46.2.186.11926

Weli, I. (2019). Student Satisfaction and Continuance Model of Enterprise Resource Planning (ERP) System Usage. International Journal of Emerging Technologies in Learning (iJET), 14(1), 71-83. https://doi.org/10.3991/ ijet.v14i01.8656

Youngberg, E., Olsen, D., \& Hauser, K. (2009). Determinants of Professionally Autonomous End User Acceptance in an Enterprise Resource Planning System Environment. International Journal of Information Management, 29(2), 138144. https://doi.org/10.1287/mnsc.46.2.186.11926

The article has been reviewed.

Received in July 2018; accepted in June 2019. 